University for Business and Technology in Kosovo

UBT Knowledge Center

UBT International Conference

2015 UBT International Conference

Nov 7th, 9:00 AM - 5:00 PM

\title{
A Study on Tibiofemoral Joint Contact Area Stresses using Finite Element Method
}

\author{
Anjeza Gjini \\ Polytechnic University of Tirana, anjezagjini@hotmail.com \\ Altin Bidaj \\ Polytechnic University of Tirana, altinbidaj@yahoo.com \\ Enio Deneko \\ Polytechnic University of Tirana \\ Drilona Disha \\ Polytechnic University of Tirana
}

Follow this and additional works at: https://knowledgecenter.ubt-uni.net/conference

Part of the Civil Engineering Commons, and the Structural Engineering Commons

\section{Recommended Citation}

Gjini, Anjeza; Bidaj, Altin; Deneko, Enio; and Disha, Drilona, "A Study on Tibiofemoral Joint Contact Area Stresses using Finite Element Method" (2015). UBT International Conference. 68.

https://knowledgecenter.ubt-uni.net/conference/2015/all-events/68

This Event is brought to you for free and open access by the Publication and Journals at UBT Knowledge Center. It has been accepted for inclusion in UBT International Conference by an authorized administrator of UBT Knowledge Center. For more information, please contact knowledge.center@ubt-uni.net. 


\title{
A Study on Tibiofemoral Joint Contact Area Stresses using Finite Element Method
}

\author{
Anjeza Gjini ${ }^{1}$, Altin Bidaj², Enio Deneko ${ }^{3}$, Drilona Disha ${ }^{4}$ \\ ${ }^{1,2,3,4}$ Polytechnic University of Tirana, Faculty of Civil Engineering \\ Department of Mechanics of Structures Tirana, Albania \\ anjezagjini@hotmail.com ${ }^{1}$, altinbidaj@yahoo.com²
}

\begin{abstract}
The joints of the human body act as mechanical or building structures joints. Joints connect different segments by enabling the movement of these segments. The design of a joint that provides durability or static support differs from that one which provides only movement. Joints of the human body, as organic joints, are considered more complex than other ty pes of joints. Finite element models help to comprehend the knee structure behavior under the action of dy namic and static loads. Deformations in the articulating cartilage and the distribution of loads from meniscus provide data to understand the effect of loads in different parts of the knee. This study aims to calculate the stresses in the contact area of the tibiofemoral joint, using the finite element model. During this process, it will be an approximation of geometric shape of the femur, tibias and articulating cartilage to their real shape, taking into account the physic-mechanical characteristics of their components. The study, based on results of numerical calculations, aims to provide practical recommendations for dimensioning the tibiofemoral articulating cartilage and for the quality of the materials, to be used in knee prosthesis industry.
\end{abstract}

Keywords: Tibiofemural joint, articulation cartilage, contact area, FEM

\section{Introduction}

In Albania, the use of prostheses is already one of the main solutions and long-term knee problems. There is no comprehensive study on the use of the method of finite element method in this field, making the analysis, treatment and control of models made abroad and methods for which there is no evidence to the technical and financial effect that they have in Albania.

In terms of engineering, finite elements method is part of modern methods of numerical analy sis. The study of this method and its application in calculation of complex structures, such as tibiofemurale node, completes the field of study and its use in the calculation of engineering structures.

The dy namics of life in developed countries has led to increased risk for knee injuries, injuries which in most cases requires local or total replacement of his prosthesis. The main factors are overweight and age damage. According to studies, in America counted on average about 700,000 cases per year of operations for total knee replacement through dentures. Expetations are that by 2030 this figure will go to 3.48 million patients / year. In European countries also counted about 230,000 cases per year. Under the same percentage they are added cases in our country.

Referring to the data obtained from INSTAT in 2014, in Albania 44\% of the population is over the age of 40 years and it tends to grow in the coming years (referring 2010, figures until 2014 have increased by 4\%). Also, referring to data obtained by the WHO (World Health Organisation) in 2008, shows that $20.4 \%$ of men and $23.1 \%$ of women in Albania are obese (age get in the study over 20 years).

Based on these data, the next few years is expected an increasment of the cases of damage to the knee node, taking main factors obesity and age, without adding other factors such as increased road accidents, negligence during physical activity, etc.

Prosthetic knee has more than three decades that was widely used in the world, with results generally excellente. Their study with finite element has taken 10-year-old recent development and is an area in advanced stage of development. 
One of the main challenges is the increasing Orthopedic medicine movement conformity in life activities of individuals who have undergone knee replacement with prosthesis. This requires the creation of models that approach as more realistic model, taking into account all factors static, kinematic and dynamic node.

\section{The Aplicated Model}

Dimensions of the model are obtained rely ing on different studies that have been done. For this stage of the study, since the aim is to analyze the constraints arising in the area of contact between the femoral cartilage and tibias, are not considered ligaments and tendons. The modeling can be done quite easily in ABAQUS.

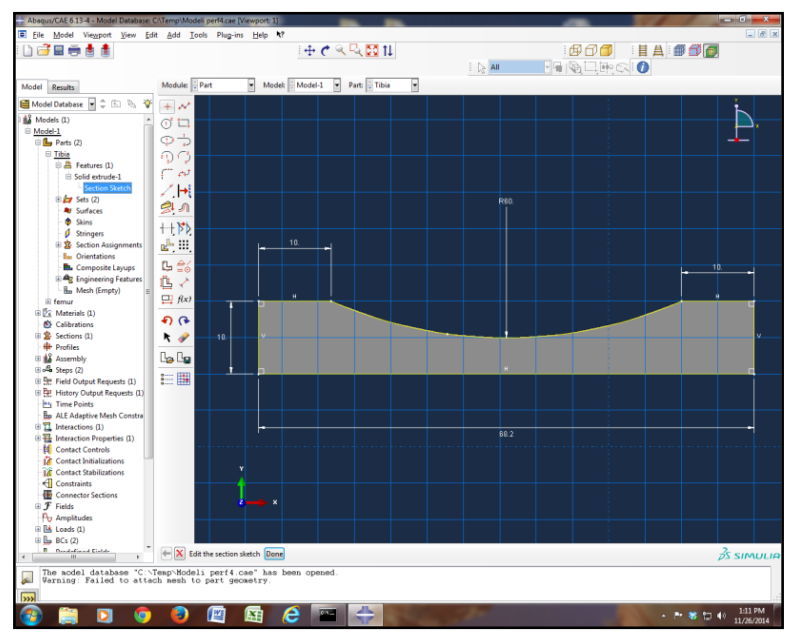

Fig. 1. Modeling of tibia cartilage

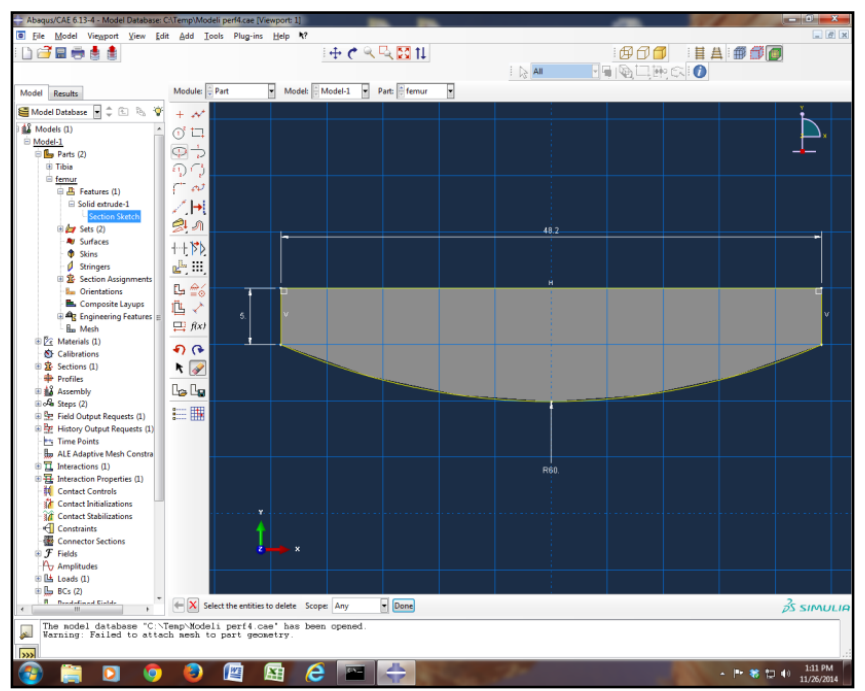

Fig. 2. Modeling of femoral cartilage 
The Mash of the element is also done in ABAQUS 6.13-4, based on the geometric model tibiofemurale node structure. As shown in the figure below, the program generated 5668 tetraedrik elements linked to 10,418 nodes.

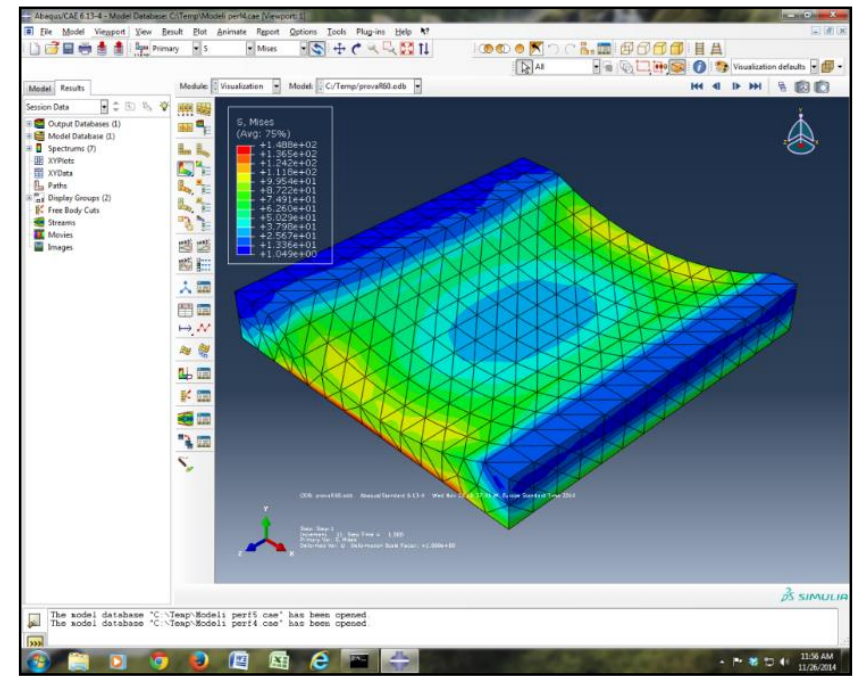

Fig. 3. Stresses in the femur-tibia contact area, R1/R2 = 1

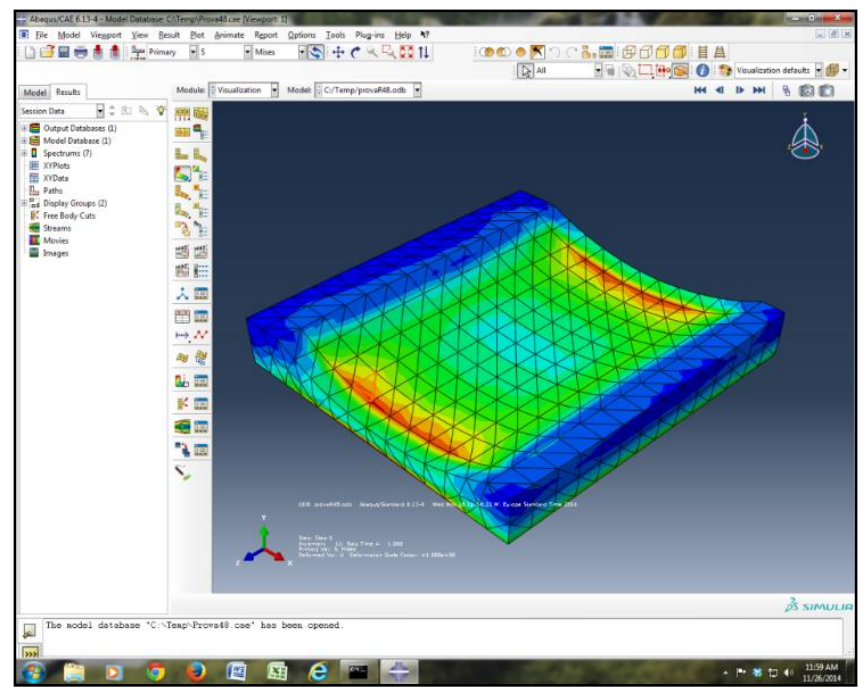

Fig. 4. Stresses in the femur-tibia contact area, R1/R2 $=1.5$ 


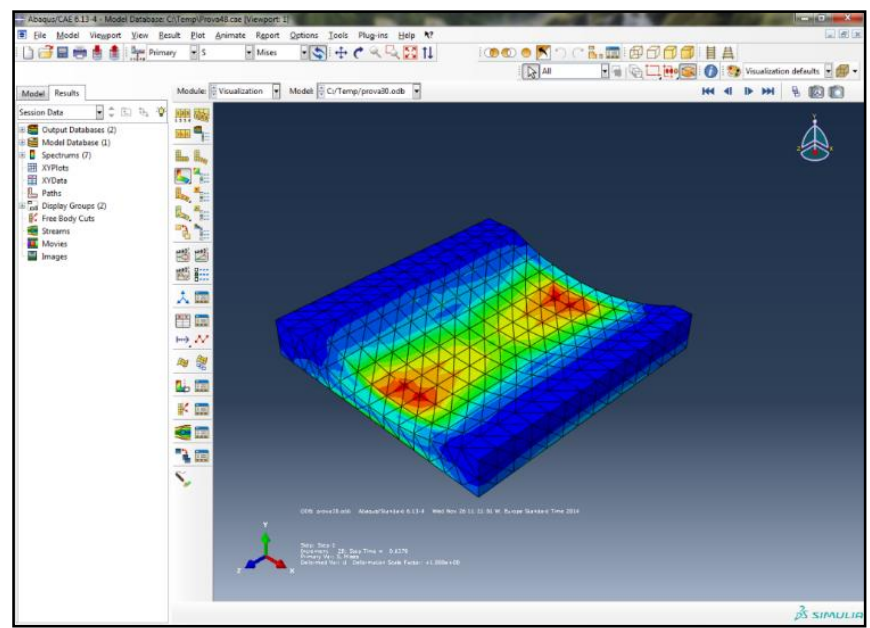

Fig. 5. Stresses in the femur-tibia contact area, R1/R2 = 2

\section{Conclusions and Results}

For this study, are taken three models to determine the stresses at the contact surface of the femoral cartilage articulation and tibias in tibiofemurale node. In each of the models is changed the femoral radius of curvature (R1), while the radius of tibias was kept constant (R2).

As it is seen from the results, with increased contact area between the tibias and femoral cartilage, reduced strains and vice versa. (as shown in Fig. 4)

From this study, it shows that, during the modeling and production of prostheses that femur and tibias, particularly cartilage articulation, have found a relationship between the size of these elements in the area of contact, to derive constraints as small during transmission Charging tibiofemurale node.

Solving static and dynamic problems for different structures by software, enables the modeling and study of more complex models of the human body. This development has provided solutions not only for studies in engineering or the medical field, but also in other interdisciplinary fields such as biomechanical.

With the growth of various accidents and not the movement of the body (for professional reasons, but not only) it has increased the need to use more and more of the implants, which should be designed with features physical and mechanical related and adaptable to the body biological.

One of the main objectives in the design of knee implants is to align the femur and tibias in order to increase the degree of conformity during movement. 


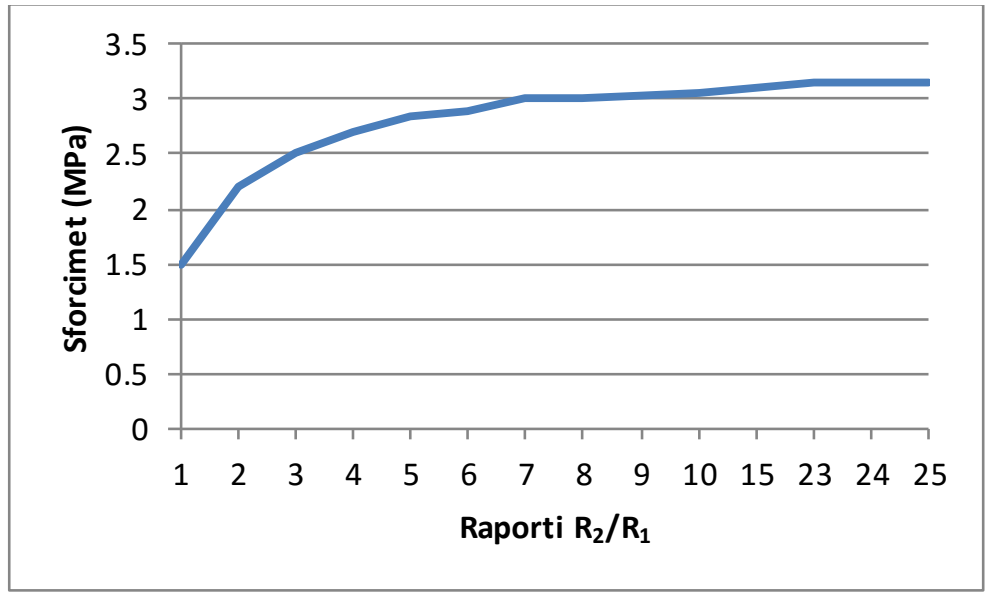

Fig. 6. The relation between stresses and R1/R2 ratio, where R1 is the femoral radius of curvature and $\mathrm{R} 2$ is the tibias radius of curvature

\section{References}

1. ABAQUS (2009). Documentation manual. ABAQUS Simulia

2. Bankoff, A.D.P. (2011). Biomechanical Characteristics of the Bone. Human Musculoskeletal Biomechanics. ISBN 978-953-307-638-6.

3. Bergmann, G., Bender, A., Graichen, F., Dymke, J., Rohlmann. A., Trepczynski, A., Heller, M.O., Kutzner, I. (2014), Standardized Loads Acting in Knee. Implants. www.plosone.org.

4. Borelli, G.A., Bernoulli, J., Elinger N., \& Joannes a Jesu, C. (1743). De Motum Animalium. Aput Petrum Gosse.

5. Butz, K. D., Chan, D. D., Nauman, E. A., Neu,C. P. (2011). Stress distributions and material properties determined in articular cartilage from MRI-based finite strains. Journal of Biomechanics 44 2667-2672.

6. Carey, R.E., Zheng, L., Aiy angar, A.K., Harner, C.D, \& Zhang, X. (2013). Subject-Specific Finite Element Modeling of the Tibiofemoral Joint Based on CT, Magnetic Resonance Imaging and Dynamic Stereo-Radiography Data in Vivo. J Biomech Eng 136(4), 041004.

7. Cerny, K. (1984). Pathomechanics of stance, clinical concepts for analy sis. Phy s.ther. 64:18511859.

8. Harris, J., \& Flanigan, D.(2011) Management of knee articular cartilage injures. Modern arthroscopy. ISBN 978-953-307-771-0.

9. Heydon, R. (2011). Finite Element Analy sis of Knee Articular Cartilage. Ryerson University. Toronto, Ontario, Canada,

10. Kauster, M., Wood, G., Stachwiak, G., \& Gächter, A. (1997). Joint load considerations in total knee replecement. J Bone Joint Surg [Br]; 79-B:109-13.

11. Kaëamura, S., Lotito, K., \& Rodeo, S.A. (2003). Biomechanics and healing response of meniscus. Operative Techniques in Sports Medicine, Vol 11, No 2: pp 68-76.

12. Luis Gracia et al. (2012). Simulation by Finite Elements of Bone Remodelling After Implantation of Femoral Stems. Finite Element Analy sis - From Biomedical Applications to Industrial Developments. ISBN 978-953-51-0474-2.

13. McGinty, G., Irrgang, J.J. \& Pezzullo, D. (2000). Biomechanical considerations for rehabilitation of the knee. Clinical Biomechanics 15: 160 \pm 166 . 
14. Nagura, T., Dyrby,C.O., Alexander, E.J., \& Andriacchi, T.P.(2002). Mechanical loads at the knee joint during deep flexion. Journal of Orthopedic Research 20 881-886.

15. Nikodem, A.\& Ścigała, K. (2012). Biomechanics of Physiological and Pathological Bone Structures. ISBN 978-953-51-0063-8.

16. Open Knee Project, www.simtk.org.

17. Roberto, P., Ventura, R., Andrea, Isis., Poiate, E.J. \& Bastos de Vasconcellos, A. (2012). Evaluation of Stress Distribution in Implant-Supported Restoration Under Different Simulated Loads. DOI: 10.5772/38971.

18. Wang, H., Zheng, Y., \& Rong, Y. (2012). Contact Stiffness Study: Modelling and Identification. Finite Element Analy sis - From Biomedical Applications to Industrial Developments. ISBN 978-953-51-0474-2.

19. Wangerin, S. (2013). Development and validation of a human knee joint finite element model for tissue stress and strain predictions during exercise. Faculty of California Poly technic State University, San Luis Obispo.

20. Xu, J., Huang, V., \& Xu, Q. (2012). The Kinematic and Static Analy sis of the Tibio-femoral Joint Based on a Novel Spatial Mechanism. International Journal of Advanced Robotic Systems. DOI: 10.5772/52943.

21. Yamaguchi, G.T., \& Zajac, F. (1989). A planar model of the knee joint. Characterize the knee extensor mechanism. J. Biomechanics Vol. 22. No. I, pp. 1. Britani e Madhe.

22. Bathe, K. J. (1996). Finite Element Procedures. Prentice Hall: Neë Jersey.

23. Becker, A. A. (1992). The boundary element method in engineering- a complete course. Mcgraw-Hill.

24. Przemieniecki, J.S., (1985). Theory of Matrix Structural Analy sis. Dover publivation, inc. New York.

25. Reddy, J.N., - An Introduction to Nonlinear Finite Element Analy sis. Oxfford University Press.

26. Stavileci, M., Pojani, N., (2006). Metoda e elementeve te fundem ne mekaniken e strukturave. Prishtine.

27. Zienkiewicz, O.C., \& Taylor, R.L., (2000). Finite element method - the basis (Vol.1, 5th edition), ButterWorth Heinemann. 